\title{
La magia del orden como autoayuda doméstica. Mandatos sociales y desigualdad de género
}

\author{
The magic of Tidying Up as domestic self-help. Social directives and gender inequality
}

Romina Cutuli ${ }^{1}$

\section{Resumen}

El best seller La magia del orden, de la japonesa Marie Kondo, ha sido epicentro y disparador de una tendencia mediática y editorial acerca del valor del orden como parte del buen vivir. Las repercusiones de la obra dieron espacio a una serie de Netflix, y otras repercusiones editoriales que mantienen a los lectores fidelizados. En este artículo se propone una lectura del fenómeno editorial y televisivo desde Argentina, como primera aproximación a una investigación de más largo aliento sobre las transformaciones y continuidades en los procesos de trabajo doméstico. El análisis fue un puntapié inicial a la consolidación de un subgénero que denominaré "autoayuda doméstica", asociado con la persistencia de una división sexual del trabajo que sobrecarga a las mujeres de tareas del hogar no remuneradas, aun cuando desarrollen actividades remuneradas fuera de hogar. Se sugiere comprender estos discursos en diálogo con la individualización propia de la subjetividad neoliberal, y a su circulación y éxito con una lógica bifronte a la vez que, refresca la visibilidad y relevancia de estas tareas impone nuevos estándares de calidad. En este sentido, la exhibición de resultados, popularizada a través de las redes sociales, tiene el riesgo de convertirse en un mandato que sobrecargue aún más a las mujeres.

Palabras clave: autoayuda, género, trabajo doméstico, revolución estancada, orden.

\section{Abstract}

The best seller The Magic of Tidying Up, by the Japanese Marie Kondo, has been the epicenter and trigger of a media and editorial trend about the value of order as part of good living. The repercussions of the work gave space to a Netflix series, and other editorial repercussions that keep readers loyal. This article proposes a reading of the editorial and television phenomenon from Argentina, as a first approach to a longer-term research on the transformations and continuities in the processes of domestic work. The analysis was a kick-off to the consolidation of a subgenre that I will call "domestic self-help", associated with the persistence of a sexual division of labor that overloads women with unpaid household chores, even when they develop paid activities outside the home. It is suggested to understand these discourses in

1 Doctora en Historia. Investigadora Adjunta del Consejo Nacional de Investigaciones Científicas y Técnicas (CONICET) - Grupo de Estudios del Trabajo, Facultad de Ciencias Económicas y Sociales, Universidad Nacional de Mar del Plata. Correo: $\underline{\text { rominacutuli@ }}$ yahoo.com.ar, ORCID: 0000-0002-8719-0921

Recibido: 12/02 2021 - Aprobado: 8/11/2021 
dialogue with the individualization of neoliberal subjectivity, and their circulation and success with a bifronted logic that, while refreshing the visibility and relevance of these tasks, imposes new quality standards. In this sense, the exhibition of results, popularized through social networks, has the risk of becoming a mandate that further overburdens women.

Keywords: self-help, gender, domestic work, stagnant revolution, order.

\section{La magia del orden como autoayuda doméstica. Mandatos sociales y desigualdad de género}

Esas ambigüedades, redundancias y deficiencias recuerdan las que el doctor Franz Kuhn atribuye a cierta enciclopedia china que se titula Emporio celestial de conocimientos benévolos. En sus remotas páginas está escrito que los animales se dividen en (a) pertenecientes al Emperador, (b) embalsamados, (c) amaestrados, (d) lechones, (e) sirenas, (f) fabulosos, (g) perros sueltos, (h) incluidos en esta clasificación, (i) que se agitan como locos, (j) innumerables, (k) dibujados con un pincel finísimo de pelo de camello, (l) etcétera, (m) que acaban de romper el jarrón, (n) que de lejos parecen moscas.

Jorge Luis Borges, El idioma analítico de John Wilkins, 1952

\section{Introducción}

La escasa originalidad de la selección del epígrafe no va en desmedro de su pertinencia. Es frecuente remitir a la cita borgiana para pensar los desafíos de la clasificación. El diseño de la vivienda familiar moderna es una taxonomía de espacios y funciones. Los hogares se habrían tornado en el siglo xxI en espacios indómitos. Viviendas urbanas en reducción en virtud del creciente valor de las propiedades; mujeres de sectores medios y altos con menos tiempo para realizar el trabajo doméstico, pero con responsabilidades que no se reducen; y un consumismo que ocuparía los espacios hasta la saturación. Estos serían algunos de los emergentes que contribuyeron al éxito de los libros La magia del orden (LMDO) (2014) y La felicidad después del orden (LFDO) (2016), y la serie ¡A ordenar! (2019). Ordenar, el primer paso de toda tarea doméstica, sería la clave de ese Leviatán que se nos rebela a diario.

Dado que ordenar implica clasificar, allí se destinarán los mayores esfuerzos argumentales de los textos y la serie con formato de "reality show" (La telerrealidad o TV de vida real). La autora propone técnicas y, ante todo, una taxonomía.

Este artículo propone una primera aproximación a la cual se denomina "autoayuda doméstica”, subgénero cuyo exponente más exitoso sería la producción de Marie 
Kondo. Estos discursos formarían parte de una nueva mirada acerca de la organización doméstica, dirigida a simplificar y estandarizar los procesos de trabajo doméstico. La hipótesis que guía estas aproximaciones a los discursos y prácticas en torno al orden doméstico, es que estas nuevas formas de gestión del trabajo doméstico proliferan en un escenario de "revolución estancada" (Hochschild, 1989; Wainerman, 2005), en la que el trabajo doméstico sigue recayendo mayoritariamente sobre las mujeres, tanto en los aspectos de gestión como de ejecución. Este escenario sería tierra fértil para propuestas que prometen simplificarlo mientras su redistribución se percibe como un horizonte lejano.

El modelo de mujer autosuficiente entra en tensión con la experiencia cotidiana del trabajo doméstico, que sigue feminizado, y la obligación de conciliarlo con las múltiples tareas de trabajo remunerado y de cuidado. La posibilidad de lograr una gestión eficiente del trabajo doméstico emerge en la forma de discurso de autoayuda y con el añadido de la promesa de "felicidad" que viene después de lograrlo.

En este sentido, se observa también una tensión entre la necesidad de encontrar formas eficientes de gestionar las múltiples demandas que recaen sobre las mujeres, entre ellas el trabajo doméstico, y su transformación en un mandato de éxito que centraliza la responsabilidad en el individuo incapaz de adoptar los preceptos que ese discurso propone. Así, si el tiempo para realizar todo el trabajo doméstico no alcanza, no es por su desigual distribución social y familiar, sino por su inadecuada gestión. De este modo, al mismo tiempo que quienes logran apropiarse de estos preceptos valoran de manera positiva esa transición, el "método" muta en mandato y favorece la culpabilización individual de quien no puede alcanzar dichos estándares.

En este trabajo se exploran estos discursos como parte del subgénero de "autoayuda doméstica", contemplando las particularidades de los discursos de autoayuda dirigidos a las mujeres. Se analiza cómo se construye una subjetividad neoliberal femenina, proponiendo nuevas formas de relacionarse con lo doméstico; la sistematización de los procesos de trabajo doméstico propuesta en la obra y, por último, algunas interpretaciones ligadas al éxito editorial occidental de la autora japonesa.

\section{Revisión de la literatura}

\section{Género, autoayuda y "revolución estancada"}

El género literario de la prescripción doméstica no es, desde luego, una novedad de nuestros tiempos. Los manuales de economía doméstica, más amplios en sus alcances y explícitos en el público al que se dirigían, comprendían estos saberes, recuperados en los hogares con éxitos disímiles. La gestión "fordista" del hogar, desplegada a través de un modelo de mujer doméstica de dedicación exclusiva, promovió el cuidado del espacio doméstico como espejo de la capacidad de la mujer como esposa y madre para 
construir y ofrecer un hogar feliz para los suyos (Pérez, 2012; Caldo, 2009 y 2017; Pite, 2016). Ese orgullo abnegado parece lejos del hedonismo que prima en las publicaciones y repercusiones mediáticas de Marie Kondo, donde el orden es la puerta de entrada a la propia felicidad.

Diversos autores se han encargado de analizar el rol de los discursos de autoayuda en la conformación de una subjetividad neoliberal (Erenrheich, 2009; Illouz, 2011; Papalini, 2015; Fridman, 2019; Torres, 2019) centrada en las capacidades y limitaciones del individuo para gestionar su propio proyecto vital, lo que conlleva, como contraparte, el tránsito de la responsabilidad individual a la culpa. Los discursos de autoayuda han tenido a lo largo del siglo Xx sesgos de género evidentes. Podría hablarse de una autoayuda pública y una autoayuda privada. Los discursos que ofrecían soluciones relacionadas con la gestión de la vida social y el management apuntaban mayoritariamente a varones, mientras que aquellos vinculados con la gestión de las emociones y las relaciones personales, se dirigían a las mujeres (Hochschild, 2008; Illouz, 2011).

A grandes rasgos, puede plantearse que, en la primera mitad del siglo $\mathrm{xx}$, emerge la autoayuda empresaria y masculina y, en la segunda mitad del siglo xx, con creciente presencia de la autoayuda privada íntima y femenina. En ambos casos el centro de los discursos habría estado en la gestión de las relaciones personales. En este sentido, una de las novedades discursivas de Marie Kondo es que pone su atención en el modo de relacionarnos con los objetos. Para incorporar a Kondo en el género de autoayuda, recuperamos la clasificación de Murillo (2006), quien advierte que a las esferas de lo público y lo privado debe incorporarse la de lo doméstico, puesto que la noción de "vida privada" no describe con justicia el espacio de opresión y trabajo invisibilizado que implica el espacio de lo privado para las mujeres. En esta línea, proponemos sumar a la demarcación precedente entre una autoayuda pública y una autoayuda privada, la existencia de una autoayuda doméstica, de la que las obras de Marie Kondo serían el exponente con mayor repercusión.

Los discursos de autoayuda para mujeres habrían mutado, a lo largo de su medio siglo de existencia, de manuales para convertirse en la esposa perfecta, en que confluyen las habilidades domésticas, maternales y amatorias hasta otorgar un espacio creciente a los aspectos emocionales del matrimonio, pero al mismo tiempo depositando toda la responsabilidad de su funcionamiento en la gestión de las mujeres. El matrimonio respecto a estas lógicas es, sin duda, un "trabajo emocional".

Acaso estos mismos modelos de relación, en los cuales el éxito de las mujeres estaba supeditado a algo tan inasible como la felicidad ajena, moldearon la dependencia emocional que la autoayuda del último tercio del siglo xx se esforzó en desarmar (Hochschild, 2008). El imperativo del amor propio y la consecución de un proyecto de vida autónomo parecía más afín a esas mujeres que proyectaban sus biografías cada vez menos en el modelo del ama de casa de tiempo completo. Con todo, las 
transformaciones en el mundo de la producción no se reflejaron en el mundo doméstico, dando lugar a una sobrecarga de tareas y responsabilidades en que se fusionaron los múltiples mandatos del ama de casa, esposa y madre de mediados del siglo xx con un mundo de la producción construido en base a lógicas masculinas de dedicación, compromiso y productividad.

Para sobrecargar(nos) aún más, la intensificación de un modelo de belleza en que priman la delgadez y la eterna juventud requiere para su consecución de tiempo y dinero. Más que reemplazarse, a lo largo del siglo xx se habrían ido superponiendo mandatos. Las mujeres debían ser buenas madres, esposas y amas de casa, aunque tuvieran dos o tres horas diarias para hacer lo que sus abuelas habían hecho de tiempo completo, trabajadoras con el mismo nivel de compromiso que sus colegas varones - aunque persistieran las segregaciones verticales y horizontales y siguieran siendo las principales responsables del cuidado - y mujeres estética y sexualmente atractivas desde el parámetro de modelos que se dedicaban a ese objetivo de tiempo completo y con abundancia de recursos económicos (Despentes, 2012).

No es de extrañar que el principal resultado de este rompecabezas de piezas imposibles de encajar sea la frustración por no poder armarlo. El trabajo doméstico se acumula en cada cuarto de la casa. No hay ni tiempo ni energía para sostener vínculos afectivos en la pareja y con los hijos. El trabajo remunerado no es la panacea de la realización personal que debería. El agotamiento se dibuja en el rostro, revelando el paso de los años. Los alimentos ultraprocesados que la publicidad y la falta de tiempo para comprar y elaborar nos tientan a consumir, dejan sus residuos en los contornos de los cuerpos. Toda una fábrica de frustración.

En este escenario de mandatos incumplibles y jornadas laborales que nunca acaban, no sorprende que sea bien recibido un "método" que promete hacer menos agotador el trabajo doméstico. A falta de políticas de cuidado, distribución equitativa del trabajo doméstico y reducción de las jornadas y exigencias laborales, es necesario encontrar la forma de hacer en una o dos horas lo que había demandado una jornada completa hace dos generaciones. La "autoayuda doméstica", como la denomino aquí, no explicita su público, pero acumula incontables guiños generizados. En lo que sigue, me ocuparé de identificar cómo este discurso promete a las mujeres —aunque no siempre desde las demarcaciones explícitas - alcanzar la felicidad mediante la eficacia doméstica.

\section{Materiales y métodos}

Los libros LMDO (2014), LFDO (2016) y la serie ¡A ordenar! (2019) serán analizados en este artículo como exponentes de la autoayuda doméstica. Aunque existen más productos vinculados con la autora, se ha decidido acotar el corpus de análisis a los tres mencionados, dadas las dimensiones de su repercusión. LMDo ha sido traducido a más de 30 lenguas y se han vendido más de tres millones de ejemplares. 
En Argentina fue el décimo libro más vendido en 2016 (Cien Radios, 2016) y el libro de autoayuda más vendido en 2017 (Clarín, 2017). Aunque LFDO no lo iguala en ventas, propone una continuidad del diálogo iniciado con una comunidad de lectores ya fidelizada. La serie ¡A ordenar! fue, por su parte, el reality más visto en Argentina a través de la plataforma Netflix durante 2019 (Filonews, 2019).

La serie es un exponente y a su vez un disparador del éxito, popularizando aún más los discursos del orden, lo que resulta evidente a través de la presencia de la autora y el tema del orden en medios de comunicación y redes sociales.

Según los datos de Google Trends, el estreno de la serie provocó un pico de búsquedas tanto de la autora (imagen 1) como del libro LMDO (imagen 2). El más alto nivel de búsquedas del título del libro que de la autora, notorio antes del estreno de la serie, da cuenta de la popularización de Marie Kondo a partir de la serie televisiva, que permitió poner rostro de manera masiva a la persona detrás de libro. Cabe observar, además, que los picos anteriores corresponden a los meses de enero, mes asociado en esta región tanto con la lectura libre como con el acondicionamiento del hogar, por ser período de vacaciones escolares y administrativas.

Interẻs a lo largo del tiempo

$\pm\langle<$



Imagen 1: Estadísticas de búsqueda de Google Trends "Marie Kondo", últimos cinco años.

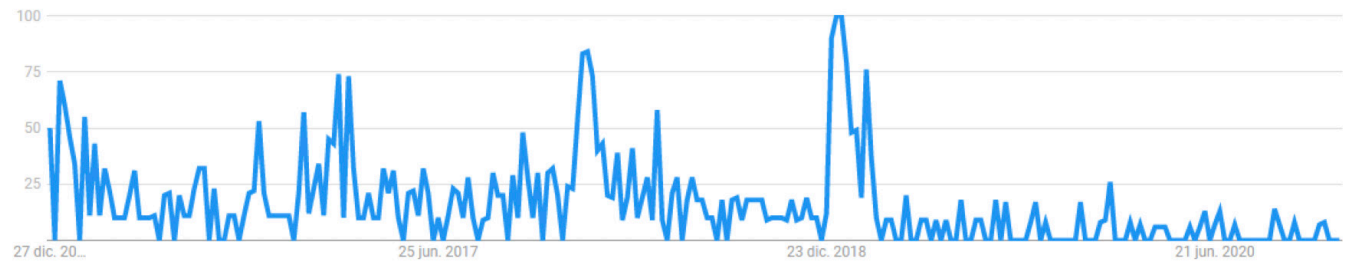

Imagen 2: Estadísticas de búsqueda de Google Trends "La magia del orden", últimos cinco años (dic. 2015-dic. 2020). 
Abordaremos los discursos del orden de Marie Kondo como autoayuda doméstica, en tres claves de análisis. En primer lugar, identificaremos su inscripción en los discursos de autoayuda que afianzan la construcción de una subjetividad neoliberal centrada en la autogestión de la felicidad. En segundo, ahondaremos en los procesos de trabajo propuestos para lograr la eficacia doméstica. Por último, nos preguntamos sobre cómo opera la circularidad cultural en el éxito de la propuesta editorial y televisiva, al emerger a través de diversos guiños la especificidad del saber de la autora en relación con su nacionalidad.

Las líneas interpretativas propuestas tendrán como hilo conductor la intención de identificar continuidades discursivas al interior de los textos y en diálogo con otros productores de subjetividad contemporáneos, en línea con las propuestas de "análisis crítico del discurso" (Fairclough y Wodak, 2013) y la construcción de un "orden del discurso" (Foucault, 2005) que, crea y refuerza demarcaciones interseccionales sobre los modos adecuados de habitar el espacio doméstico y gestionar su mantenimiento y cuidado. Como herramienta complementaria a la lectura, nos valdremos del Atlas.ti 9.o para identificar recurrencias y relaciones al interior de los textos. Las referencias textuales a partir de palabras clave y la cuantificación de ocurrencias de términos han sido, en todos los casos, identificadas con el citado software.

\section{Resultados y discusión}

\section{a. Orden y felicidad, en ese orden}

"La vida solo empieza verdaderamente después de poner orden en la casa", declara Marie Kondo (2016, p. 6) al comienzo de su libro LFDO, en el que avanza sobre los preceptos ya vertidos en LMDO. Allí refiere, en un giro habitual en los libros de autoayuda, diversos testimonios que confirman el efecto "mágico" del orden del hogar:

"Después de tu curso, renuncié a mi trabajo y abrí mi propio negocio, algo con lo que había soñado desde niño."

"Tu curso me ayudó a ver lo que en verdad yo necesitaba y lo que no. Así que me divorcié y ahora me siento mucho más feliz."

"Alguien a quien yo quería contactar hace poco me contactó a mî"

"Me complace informar que, desde que organicé mi apartamento, he logrado de veras incrementar mis ventas".

"Mi esposo y yo nos llevamos mucho mejor". 
"Me sorprende descubrir que el solo hecho de tirar cosas me haya cambiado tanto".

"Por fin he logrado bajar tres kilos". (Kondo, 2014, p. 4)

Como señala Papalini (2015), los testimonios constituyen un elemento crucial de la narrativa de autoayuda. En sintonía con la pretensión transformadora del género, la lectura y puesta en práctica de los saberes vertidos en estos libros, implican parteaguas radicales en la vida de quienes se dejan atravesar por ellos. El anverso implícito de esta prédica es que, si a un sujeto no le sucede eso, se deberá a que no siguió adecuadamente el procedimiento. La ineficacia siempre radicará en el individuo.

El discurso de autoayuda promete el fin de las reincidencias: no más desorden, no más dietas, no más vínculos abusivos, no más berrinches infantiles. La lista podría prolongarse, confluyendo en el denominador común de la solución definitiva, el camino sin retornos ni desvíos hacia la plenitud. La "garantía de cumplimiento", a la vez personalizada y universal, disponible para todo el que quiera abrazarla (Papalini, 2015, p.143).

En la medida que estos discursos se proponen como modos de transformación y autotransformación vital a partir de un aspecto de ella -en nuestro caso, el orden doméstico - ese lenguaje común pone en diálogo al autor con los lectores, pero también a la comunidad de lectores entre sí, que intercambia saberes y experiencias a través de redes sociales, prescribiendo, describiendo y evaluando a través de ese saber y jerga específicos.

Este tipo de discurso de autoayuda pasa de proponer una transformación integral del ser, a prometer su concreción partiendo de una faceta de la vida cotidiana - desde la hora de levantarse hasta el modo de organizar las tareas diarias-.

Esa transformación concreta irradiará, prometen, en el conjunto de la vida de los sujetos que la implementan. La otra cara de la moneda implícita en estos discursos es que, si ofrecen la fórmula de la felicidad y logran venderla con tal éxito, existe un sustrato fértil en la insatisfacción de cierto público — supondremos, en este caso, mujeres de sectores económicos y educativos medios y altos - con su presente. Friedan (1965/2016) en adelante mucho se ha dicho sobre el malestar de las mujeres frente a la domesticidad. Lo novedoso de los discursos del orden no es el diálogo implícito con esta frustración de larga data, sino el carácter de su propuesta. Acaso individualizante y conservadora, se dirige a quien se ocupa del orden doméstico prometiendo, no la redistribución ni la liberación de ese trabajo, sino su transformación en un trabajo gratificante.

La felicidad constituye un eje estructurante de la propuesta y posiblemente, una de las claves de un éxito que atravesó las fronteras nacionales. Su título en inglés, 
Spark joy, y en alguna medida también su traducción al español, LMDO, se apropian de un discurso centrado en la afirmación positiva y en el bienestar. Vale explicitar el contraste entre la propuesta de Kondo y de quien fuera su inspiradora, apenas conocida en Occidente justamente por esta función, pese a haber publicado a principios de siglo, cuando Kondo era una adolescente.

El arte de tirar, de Tatsumi (2016), ni siquiera había sido traducido al español hasta que Kondo le otorgó trascendencia refiriéndolo como una de sus fuentes de inspiración. Desde el propio título hasta el desarrollo de la propuesta, la diferencia será radical. Si bien la caricaturización de la propuesta de Kondo recupera de modo a veces hilarante la práctica del descarte, la autora destaca la decisión de elegir qué conservar, con 140 menciones entre LMDO y LFDO, antes que ofrecer argumentos para desechar, con 121 menciones entre los dos libros.

La estructuración de una propuesta de orden centrada discursiva en el conservar - aun cuando la práctica de tirar cobre inevitable protagonismo en la aplicación del "método Konmari" - es un pilar fundamental de la obra. En línea con los discursos sobre la gestión de la felicidad, se invita a "focalizarse en los aspectos positivos" (Cábanas e Illouz, 2019, p.126) que, en el lenguaje de la autora se traduce como "quédate con lo que te hace feliz".

Recuperando una estructura recurrente en la literatura de autoayuda, el orden no se presenta como fin en sí mismo, sino como el método para alcanzar la felicidad. El $40 \%$ de las menciones relacionadas con conservar aparecen vinculadas con felicidad mientras que, en el caso de desechar, ese porcentaje se reduce al $34 \%$. Entre los dos libros, el 33\% de las menciones de orden aparecen asociadas con felicidad.

Amén de proponer que se alcanzará la felicidad luego de ordenar, procura transmitir el proceso de trabajo como una experiencia placentera. En un clima cultural donde la abnegación femenina es asociada con el trabajo, resulta eficaz proponer como placentera la realización de la tarea doméstica que es la madre de todas las demás. Los relatos de la vida cotidiana que se traslucen en la vida que comienza luego de la implementación del método Konmari transmiten paz, felicidad, placer y hedonismo.

Un aspecto destacable es el optimismo que emerge de la narración de tareas habitualmente representadas como desagradables. Aunque en sus textos también está presente, se evidencia con mayor intensidad en la serie el entusiasmo sobreactuado frente al intenso desorden que caracteriza a los espacios domésticos donde es convocada a intervenir. Sonriendo y con un gesto de manos que mixtura un delicado aplauso y un saludo oriental, expresa que le gusta el desorden porque "le encanta ordenar" (Kondo, 2019). 
Así, invita a entender como un agradable desafío esas pilas de papeles y de ropa que por lo general desalientan a avanzar en la concreción de las tareas domésticas. En su discurso da especial protagonismo al hecho de no ordenar para otros, lo que de algún modo presenta una paradoja respecto del servicio remunerado que ella misma presta. A partir de su experiencia personal como ordenadora compulsiva, alienta a enfocarse solo en el desorden propio y apostar a que los miembros de la familia sigan los pasos de quien inicia el proceso y que, a juzgar por su propia experiencia, sería una mujer: "Como si te siguieran los pasos, ellos empezarán a deshacerse de pertenencias innecesarias y a organizar sin que tengas que expresar una sola queja. Quizá suene increíble, pero cuando alguien empieza a organizar, detona una reacción en cadena" (Kondo, 2014, p. 37).

La "magia" de la imitación propuesta por la autora contrasta con las arduas negociaciones domésticas que son relatadas en diversos abordajes sobre la organización del trabajo doméstico (Kauffmann, 1999; Wainerman, 2005; Alfonsi et al., 2007). La concentración del discurso en los aspectos positivos del proceso de orden y la felicidad como resultado, insertan sin dudas la producción de la autora en el género de autoayuda. Si bien la vulgata popular sobre la propuesta recupera la práctica de tirarlo todo, el esfuerzo discursivo por concentrarse en lo que sí queda en casa es recurrente. En este sentido jerarquiza la felicidad por encima de la utilidad, otorgando a las emociones un plus sobre la razón y, al mismo tiempo, mayor valor a los objetos como parte de un universo de relaciones.

El carácter "mágico" de la propuesta comprende además otra cara menos visible del discurso de autoayuda contemporáneo: su estandarización. Las propuestas no sólo son individualistas (Simonds, 1992) -en el caso que nos ocupa, ni atisbo de pensar que el desborde hogareño pueda provenir de la desigual distribución de las tareas domésticas- sino que prometen una única fórmula eficaz más allá de las particularidades de cada sujeto (Cábanas e Illouz, 2019).

Marie Kondo insiste en fundamentar este punto, relatando que las búsquedas por hallar métodos personalizados han sido tan infructuosas como ineficaces, y en definitiva los hogares y las personas, en lo que al orden respecta, no se diferencian tanto unos de otros. Bajo el subtítulo "No cambies el método para ajustarlo a tu personalidad" (Kondo, 2014, p.19), la autora explica su equívoca trayectoria procurando adecuar los métodos de orden a las personalidades de sus clientes como parte de un proceso de aprendizaje que, mediante ensayo y error, la habría llevado a la sabia conclusión de estandarizar. Así, en lo que a orden respecta, la clasificación de la humanidad es bastante sencilla:

Según este enfoque, a la gente que no puede mantenerse organizada podemos clasificarla sólo en tres tipos: el de no puedo deshacerme de las cosas, el de no puedo volver a poner las cosas en su sitio y el de la combinación de los dos anteriores. Al observar a mis clientes, 


\section{GÉNERO E INTERCULTURALIDAD}

me di cuenta de que 90 por ciento pertenece a la tercera categoría -"no puedo deshacerme de las cosas ni puedo volver a ponerlas en su sitio"-, mientras el 10 por ciento restante cae dentro del tipo de "no puedo volver a poner las cosas en su sitio". (Kondo, 2014, p. 21)

Semejante estandarización, con un nivel de amplitud que lo abarca todo sin especificar nada, parece lograr el efecto de identificación que provoca la literatura de autoayuda: están hablando de mí.

Recuperando una vez más la demarcación de Murillo (2006) entre público, privado y doméstico para hacerla extensiva a la autoayuda, las "garantías de felicidad" (Papalini, 2015) tendrían el potencial de trascender el espacio donde intervienen. Es significativo en ese aspecto el subtítulo de la edición en español de LMDo: "Ordena tu casa, ordena tu vida”. Es decir, esa autoayuda doméstica constituye la puerta de entrada para una transformación integral, en suma, la puerta de entrada a la felicidad definitiva.

\section{b. El proceso de producción del orden}

Lo radical y definitivo son medulares a los discursos de autoayuda. La aplicación de las propuestas que contienen - en muchos casos con un nivel de abstracción que hace ardua su traducción práctica - prometen cambiar, a partir de la parte, el todo, y hacerlo para siempre. Una lógica sinecdótica atraviesa el discurso de autoayuda, en la medida que esa propuesta de cambiar el todo a partir de la parte se sustenta en la convicción de que la parte expresa algo sustancial sobre el todo. En los discursos que nos ocupan, "el placard es el reflejo de la salud mental" (La Nación, 2011) y, otras afirmaciones similares, permiten revertir la operación, transformando a partir del reflejo.

En una propuesta centrada en el trabajo doméstico, el carácter definitivo tiene una particularidad vinculada con que, más allá del dinamismo del propio ciclo vital, lo definitivo entra en franca contradicción con la esencia del trabajo doméstico. A diferencia del sistema de producción fordista, lo repetitivo del trabajo doméstico no se ciñe exclusivamente a la actividad realizada, sino a lo efímero de su resultado, que obliga a repetirla una y otra vez.

En la icónica escena de Tiempos Modernos (Chaplin, 1936), Charlot sufre hasta la locura la alienación de repetir una y otra vez la tarea de ajustar una tuerca, pero nunca es la misma tuerca. Lo que obstaculiza la identificación con el trabajo es su fragmentación, su distanciamiento del resultado final (Coriat, 1998). Ello no significa que no haya un resultado trascendente, lo hay, mas la división del trabajo le impide sentirse como partícipe de ese resultado. En el trabajo doméstico la situación es bien diferente. En el hogar, el ama de casa se baña dos y miles de veces en el mismo río de ropa por lavar, camas por tender, trastos por guardar y pisos por fregar. 
Así, el trabajo doméstico puede incluirse en el espectro de lo que Arendt (1953/2016) denominara labor y en nuestros días resulta más familiar denominarlo "sostenibilidad de la vida" (Carrasco, 2001). Siguiendo la clasificación de la filósofa, la labor constituiría el más bajo de los escalafones de la vida activa y, en definitiva, el que menos nos distingue en nuestra condición humana. En su sistema de pensamiento, "labor" y "trascendencia" constituyen un oxímoron. Ello explicaría los históricos esfuerzos de los privilegiados por despegarse de esa función tan necesaria como desvalorizada, y que en todo sistema social habría estado segregada en sujetos subalternizados: esclavos, sirvientes, mujeres.

El discurso de Marie Kondo acierta con la frustración correcta frente al agobio del trabajo doméstico: siempre hay que volver a hacerlo. La "garantía de felicidad" (Papalini, 2015) en la propuesta de Kondo es convertir labor en "work".

Un método revolucionario para que la repetitiva tarea del orden se convierta, en definitiva. No es intrínseco al orden que sea labor, sino a la falta de un método eficiente: "Si crees que la organización es una labor interminable que debe hacerse todos los días, estás muy equivocado" (Kondo 2014, p. 20).

Valiéndose de otro recurso propio del discurso de autoayuda, narra su camino de búsqueda personal hacia el modo óptimo de gestionar el universo doméstico, tomando conciencia de la condición de labor del orden a través de la práctica: "Cuando de cocina o costura se trata, la práctica hace al maestro, pero aunque la organización también es un quehacer doméstico, yo no parecía mejorar, no importa cuán a menudo lo hiciera (nada se mantenía ordenado por mucho tiempo)" (Kondo 2014, p. 10).

Y así llega a su momento de revelación: "Cambié mi atención de la cocina y la costura -que yo consideraba la esencia de las labores domésticas-, al arte de la organización" (Kondo, 2014, p. 13).

Cabe preguntarse por qué, si la condición de labor es intrínseca al trabajo doméstico, su feminización no es precisamente una novedad y la frustración es resultado inevitable de su realización especializada y exclusiva, la segunda década del siglo xxI se presenta como el momento óptimo para convertir en éxito editorial y mediático una propuesta que interviene sobre el espacio de lo doméstico. En las décadas centrales del siglo Xx, la modernización de los hogares transitó de la mano de una transformación en el trabajo doméstico.

El ama de casa de tiempo completo y la familia conyugal nuclear se erigen como la forma hegemónica de hogar, y la transformación de los espacios procura imponer la lógica fordista al trabajo doméstico. Aunque la tecnificación del hogar (Pérez, 2012) y la mercantilización de una creciente gama de bienes y servicios (Milanesio, 2014) podrían interpretarse, en una apresurada pretensión de homologar el sistema de 
producción fabril al doméstico, afines al proceso de descualificación y estandarización de la producción.

Una diferencia crucial distingue el proceso de producción doméstico en el hogar nuclear conyugal de la producción fabril, es la imposibilidad de efectuar división del trabajo. La eficacia de la cadena de montaje estaba asociada a la subdivisión y especialización de cada una de las fases del proceso productivo. Pero en el espacio doméstico moderno, todas las funciones se condensarán en la figura del ama de casa, promoviéndose además como virtud, en la segunda mitad del siglo xx, la prescindencia de personal auxiliar para la realización de tareas domésticas (Pérez, 2012).

En esas mismas décadas, la figura del ama de casa de tiempo completo se desdibujó y si bien es demasiado prematuro asumirla como un sujeto del pasado, su hegemonía se retrajo de la mano de la mayor participación laboral de las mujeres, la crisis del trabajo, la transformación de las unidades familiares y la creciente desigualdad social.

El mayor nivel educativo impuso mayor centralidad a las carreras laborales en las vidas de las mujeres -al menos de las que accedieron a esa educación-; el desempleo y la precarización impulsaron la salida al mercado de trabajo de las mujeres casadas como "trabajadoras adicionales"; la diversificación de las unidades familiares hizo impracticable el modelo de "male bread winner" o hombre que gana el pan (Crompton, 1999) y mujer ama de casa; la creciente desigualdad social profundizó el rol doméstico y precario de las mujeres de menores ingresos, mientras crecieron las oportunidades laborales y profesionales de las de sectores medios y altos, en buena medida subsidiarios del trabajo doméstico remunerado de las mujeres de los sectores social y económicamente vulnerados.

Esa diversificación implicó un menor tiempo disponible para el trabajo del hogar en la vida de las mujeres. En los sectores medios y altos construían proyectos personales y en los de menores ingresos disputaban la subsistencia, pero el trabajo doméstico y de cuidado seguía feminizado. Esta "revolución estancada" (Wainerman, 2005) en que la mayor participación de las mujeres en el espacio público no se refleja en el hogar, consolida el trabajo doméstico y de cuidado en la forma de "segunda jornada" (Balbo, 1979; Hochschild, 1989).

Al mismo tiempo, los espacios domésticos se reducen de la mano de los procesos de gentrificación (Harvey, 2005). Si los procesos de trabajo fordistas habían sido imaginados para una vivienda que crecía en dimensiones, de la mano del creciente poder adquisitivo de las familias trabajadoras, puede presumirse su inadecuación a la reducción de tiempo y espacio propia de las unidades domésticas contemporáneas. Una vez más en clave autobiográfica, Kondo entrelaza en su discurso la experiencia adquirida en torno al orden y la construcción de un saber autodidacta en relación con el carácter 
reducido de los espacios domésticos en su tierra natal: Japón. Esta particularidad nos conduce a lo que quizás otorgue el carácter más distintivo al fenómeno Kondo.

\section{c. Una cuota extra de eficacia: el atractivo de lo exótico}

El género de autoayuda se caracteriza, además de por sus pretensiones inaugurales en la temática que propone transformar, por el uso de un lenguaje coloquial combinado con un lenguaje específico que le es propio (Papalini, 2015).

Estos giros contrastan con la llanura lingüística que les es habitual, lo que cumple con dos funciones. En primer lugar, confiere verosimilitud a través de la creación de un campo específico de conocimiento propio y original, en que las referencias bibliográficas son entre escasas y ausentes. Cuando aparecen, remiten a sujetos lejanos en tiempo y/o espacio cuyas declaraciones aparecen resignificadas.

Mayoritariamente, los autores de autoayuda vienen a contarnos un secreto que nadie ha revelado antes, ya sea porque conviene que permanezca guardado o porque sencillamente, quien lo relata es su descubridor. Es, y cumple la no menos importante función de fortalecer la pertenencia a una comunidad de lectores/practicantes. Las especificidades del lenguaje constituyen pinceladas de profesionalismo en textos de marcada coloquialidad como suelen ser los best sellers de autoayuda.

El esfuerzo puede considerarse más necesario aún en este caso, donde se aborda un asunto tan pedestre e históricamente desvalorizado como el trabajo doméstico. Con ello entra en escena la segunda función de este lenguaje especializado: la consolidación de una comunidad de lectores y practicantes del "método". La complicidad y el entendimiento con la autora y entre lectores-practicantes se fortalece a través de redes sociales donde se intercambian experiencias, consejos y exhiben resultados.

También, donde se penaliza a quienes adoptan las prescripciones con cierta flexibilidad o limitaciones materiales. La jerga acerca y distancia al mismo tiempo. Confiere una práctica de distinción (Bourdieu, 1989) que tiene, en el caso que nos ocupa, añadido el atractivo de lo exótico. De las palabras que componen esa lengua específica, se destacan algunas inventadas o resignificadas. Así sucede con konmari, acrónimo del nombre de la autora; komono, palabra japonesa que la autora utiliza como una de las categorías a conocer para desarrollar el método de manera eficaz: si no es ropa, libros, papeles ni tiene valor sentimental, todo lo que está en el hogar es komono.

En nuestras lecturas occidentales, mayoritariamente desconocedoras de la lengua japonesa, la incorporación de este tipo de términos podría producir el atractivo de las conlang, aquellas lenguas artificiales que, en los universos literarios, confieren verosimilitud y fortalecen las comunidades de lectores. 
Al recibir los términos vaciados de los usos habituales en su lengua de origen, se reapropian como parte de ese universo de saber específico. Para la comunidad lectora latinoamericana, una palabra en japonés puede ser tan ajena como una en élfico ${ }^{2} \mathrm{o}$ dothraki ${ }^{3}$, con lo cual adquiere una potencialidad de apropiación intensificada por lo exótico, lo que en el idioma original no es factible. A esta idiolengua se le suman popularizados neologismos como "marikondear", presente en las redes sociales para compartir propuestas y resultados relacionados con la aplicación de los preceptos de la autora (Ludwigsen, 2019).

El encantamiento de lo exótico aparece aún más reforzado en la serie ¡A ordenar! (Kondo, 2019). Allí Marie Kondo replica prácticas culturales de vínculo con los espacios y objetos propias de su cultura, en hogares de familias estadounidenses. Como ha ocurrido con prácticas como el yoga o la meditación, el consumo occidental las resignifica y fragmenta de la mano de la globalización (Citro et al., 2011).

El diálogo con los objetos, el saludo a la casa, prácticas en diálogo con el animismo propio del sintoísmo (Sullivan, 2008; Levi-Strauss, 2013) se incluyen en el repertorio exótico de aquella extranjera que entra a los hogares occidentales a descartar, clasificar y reubicar pertenencias, en escenarios de una abundancia que desborda. El distanciamiento cultural se preserva además mediante la presencia de una intérprete. Marie Kondo no habla inglés fluido -ni español, claro- sin embargo, no es una mera extranjera. Su éxito reside en una occidentalización que incluye la actual residencia en Estados Unidos, cuya capacidad de exportación de industrias culturales resulta evidente, más aún en América Latina.

Como señala Burke (2008) "la combinación de distancia y similitud puede ser un factor clave en el éxito de las exportaciones o, diríase, 'transplantes' culturales” (p. 144). Ese equilibrio permitiría abrir las puertas de los hogares a esta extranjera que propone una solución armónica a las tensiones emergentes de un orden de género frustrante y escasamente alterado.

\section{Conclusiones}

Los discursos del orden parecen presentarse como una respuesta no conflictiva a la injusticia de género que se cristaliza en la sobrecarga doméstica que viven las mujeres. Como efecto colateral, de estas propuestas emerge una performatividad doméstica que, en nombre de la simplificación, construye estándares acaso más exigentes del buen hacer y del espacio doméstico ideal. Al ofrecer un método cuya aplicación daría como resultado espacios propios de una revista de interiorismo, la frustración ante los espacios vividos podría volverse análoga a la construida en torno a la configuración

2 Lengua artificial del universo literario de El señor de los anillos, de J. R. R. Tolkien.

3 Lengua artificial del universo literario de Juego de Tronos, de G. Martin. 
de una belleza hegemónica, desarrollada mediante intervenciones sobre los cuerpos y sobre sus imágenes.

Por otra parte, la circulación de discursos que promueven la jerarquización profesional de ciertas tareas domésticas, queda a horcajadas entre el esnobismo y el reconocimiento de su existencia como un campo de saber. ¿Cómo contribuye a la construcción de un saber calificado? ¿Quiénes pueden asumirlo como tal, qué distingue a las expertas en orden de las trabajadoras del hogar?

Pese a no explicitar a las mujeres como su lector imaginado, diversos guiños y autorreferencias revisitan el rol doméstico de la mujer, a la vez que prometen una gestión del trabajo doméstico igualitaria. A diferencia de los tradicionales manuales de economía doméstica, prescriptivos y pedagógicos, los nuevos discursos del orden se presentan inscriptos en el marco de la literatura de autoayuda. En este sentido, cabe preguntar qué lleva a sus consumidores/lectores, mayoritariamente mujeres, a buscar bienestar a través de la búsqueda de un método eficaz de gestión del trabajo doméstico.

La primera respuesta puede ser innecesaria en términos conceptuales, pero sigue siendo relevante en términos políticos: el trabajo doméstico sigue siendo una carga mayoritariamente femenina. Las mujeres desbordadas por la doble jornada laboral en el trabajo y en el hogar, buscan formas de simplificar ese trabajo del que no puede deshacerse ni distribuir de modo más justo y eficaz. En este sentido, la inscripción de estos discursos como literatura de autoayuda es coherente con la permanencia del statu quo doméstico -y social-, al asumir la sobrecarga de trabajo doméstico como un problema de gestión ineficaz y de potencial solución individual.

Si bien el mensaje de este y todos los discursos de autoayuda es que "cualquiera podría aplicarlo", ese cualquiera sigue siendo, mayoritariamente, las mujeres que intentan estar a la vez en todos frentes de exigencia de la vida contemporánea. Tras la apropiación del método viene la exigencia de los espacios impolutos y la estética del doblado de los calcetines. Una legión de mujeres tratando de mantener a raya ese universo de posesiones anárquico y heterogéneo como la clasificación desplegada en el Emporio celestial de conocimientos benévolos. Resta desear que sea apenas un capítulo más de la "revolución estancada" y no una involución. 


\section{GÉNERO E INTERCULTURALIDAD}

\section{Lista de referencias}

Alfonsi, N., Pérez, I. y Torricella, A. (2007). "Transformaciones en la vida cotidiana. Producción y re-producción. Mar del Plata hacia fines de la década del '9o". En Norberto Álvarez (comp.) Cuestiones de familia. Problemas y debates en torno a la familia contemporánea. Mar del Plata: Eudem. Pp. 171-198.

Arendt, H. ([1953] 2016). La condición humana. Buenos Aires: Paidós.

Balbo, L. (1979). «La doppia presenza.»Inchiesta, $\mathrm{n}^{\circ} 32$.

Bourdieu, P. (1989). La distinción. Criterios y bases sociales del buen gusto. Madrid: Taurus.

Burke, P. (2008). "Algunas reflexiones sobre la circularidad cultural", Historia Social, (6o), pp. 139-144. http://www.jstor.org/stable/40657997. Última visita: 12 de febrero de 2021.

Cábanas, E. e Illouz, E. (2019). Happycracia. Cómo la ciencia y la industria de la felicidad controlan nuestras vidas. Barcelona: Paidós.

Caldo, P. (2009). Mujeres cocineras. Hacia una historia sociocultural de la cocina argentina hacia fines del siglo XIX y principios del XX. Rosario: Prohistoria.

Caldo, P. (2017). Un cachito de cocinera. Mujeres, libros y recetas en la Argentina. Buenos Aires: Casagrande.

Carrasco C. (2001). "La sostenibilidad de la vida humana, ¿un asunto de mujeres?". Mientras tanto, 82, otoño-invierno. Pp. 43-70. En internet: https://www.jstor. $\mathrm{org} / \mathrm{stable} / 27820584$. Última visita: 12 de febrero de 2021.

Chaplin, C. (1936). Tiempos modernos. Charles Chaplin Productions: Estados Unidos.

Cien Radios. (2016). "Diez libros más vendidos de Argentina". 1 de noviembre. https:// libros.cienradios.com/10-libros-mas-vendidos-de-argentina/

Citro, S., Ascheri, P., \& Mennelli, Y. (2011). "El multiculturalismo en los cuerpos y las paradojas de la desigualdad poscolonial". Boletín de Antropología Universidad de Antioquia, 25(42), 102-128. https://www.redalyc.org/pdf/557/55722568004. pdf. Última visita: 12 de febrero de 2021.

Clarín. (2017). "Género por género, los libros más vendidos en 2017". 23 de diciembre. https://www.clarin.com/cultura/genero-genero-libros-vendidos-2017_o_r1KbnxjzM.html 
Coriat, B. (1998). El taller y el cronómetro. Ensayo sobre el taylorismo, el fordismo y la producción en masa. Madrid: Siglo XXI.

Crompton, R. (1999). RESTRUCTRING GENDER RELATIONS AND EMPLOYMENT. Oxford: University Press.

Despentes, V. (2012). Teoría King Kong. Buenos Aires: El Asunto.

Erenrheich, B. (2009). Sonríe o muere. Madrid: Turner.

Fairclough, N., y Wodak, R. (2013). Critical discourse analysis. Los Angeles: Sage.

Filonews. (2019). "Estas son las series y películas de Netflix más vistas en Argentina". https://www.filo.news/cine-y-series/Estas-son-las-series-y-peliculas-deNetflix-mas-vistas-en-2019-en-Argentina-20191230-0029.html

Foucault, M. (2005). El orden del discurso. Buenos Aires: Tusquets.

Fridman, D. (2019). El sueño de vivir sin trabajar. Una sociología del emprendedorismo, la autoayuda financiera y la subjetividad neoliberal. Buenos Aires: Siglo XXI.

Friedan, B. ([1965] 2016). La mística de la feminidad. Madrid: Cátedra.

Harvey, D. (2005). Ciudades rebeldes: del derecho a la ciudad a la revolución urbana. Madrid: Akal.

Hochschild, A. (1989). The second shift. New York: Viking.

Hochschild, A. (2008). La mercantilización de la vida íntima. Apuntes de la casa y el trabajo. Buenos Aires: Katz.

Illouz, E. (2011). La salvación del alma moderna. Terapia, emociones y la cultura de la autoayuda. Buenos Aires. Katz.

Kauffmann, J-C. (1999). "La ropa sucia". En Ulrich Beck (comp.) Hijos de la libertad. Buenos Aires: FCE. Pp. 211-246

Kondo, M. (2014). La magia del orden. Herramientas para ordenar tu casa y tu vida. Buenos Aires: Planeta.

Kondo, M. (2016). La felicidad después del orden. Buenos Aires: Planeta.

Kondo, M. (2019). ¡A ordenar! Netlix: California. 
La Nación. (2011). Entrevista/Pilar Sordo. "El placard es el reflejo de la salud mental". 13 de octubre de 2011. En internet: https://www.lanacion.com.ar/moda-y-belleza/ el-placard-es-el-reflejo-de-la-salud-mental-nid1414082/

Levi-Strauss, C. (2013). La otra cara de la luna. Madrid: RBA pensamiento.

Ludwigsen, K. (2019). "Marie Kondo and the New Self-Help" (2019). Book Publishing Final Research Paper. 45. https://pdxscholar.library.pdx.edu/eng_bookpubpaper/45. Última visita: 12 de febrero de 2021.

Milanesio, N. (2014). Cuando los trabajadores salieron de compras. Buenos Aires: Siglo XXI.

Murillo, S. (2006). El mito de la vida privada. De la entrega al tiempo propio. Madrid: Siglo XXI.

Papalini, V. (2015). Garantías de felicidad. Buenos Aires: Adriana Hidalgo Editora.

Pérez, I. (2012). El hogar tecnificado. Buenos Aires: Biblos.

Pite, R. (2016). La mesa está servida: Doña Petrona C. De Gandulfo y la domesticidad en Argentina. Buenos Aires: Edhasa.

Simonds, W. (1992). Women and Self-Help Culture. Nueva Jersey: Rutgers UP.

Sullivan, L. (2008). Naturaleza y rito en el sintoísmo. Donostia: Nerea.

Tatsumi, Nagisa. (2016). El arte de tirar: cómo librarse de las cosas sin sentimiento de culpa. Madrid: Duomo.

Torres, M. (2019). Neoliberalismo y subjetividad: una genealogía de la felicidad y la autoayuda moderna. Bogotá: Universidad Pedagógica Nacional.

Wainerman, C. (2005). La vida cotidiana en las nuevas familias, ¿una revolución estancada? Buenos Aires: Lummiere. 